\title{
Sensitivity of Molecular Packing and Photovoltaic Performance to Subtle Fluctuation of Steric Distortions within D-A Copolymer Backbones
}

\author{
Jianhong Gao, ${ }^{\dagger}$ Wei Wang, ${ }^{\dagger}$ Shubin Liu, ${ }^{\ddagger}$ Chun Zhan $^{\dagger}$ Shengqiang Xiao, ${ }^{*}{ }^{\dagger} \odot$ Xinhui Lu, ${ }^{*}$, \\ and Wei You ${ }^{*},+, \|$ (1) \\ ${ }^{\dagger}$ State Key Laboratory of Advanced Technology for Materials Synthesis and Processing, Wuhan University of Technology, Wuhan \\ 430070, P. R. China \\ ${ }^{\ddagger}$ Research Computing Center, University of North Carolina at Chapel Hill, Chapel Hill, North Carolina 27599-3420, United States \\ ${ }^{\S}$ Department of Physics, Chinese University of Hong Kong, Hong Kong, P. R. China \\ "Department of Chemistry, University of North Carolina at Chapel Hill, Chapel Hill, North Carolina 27599-3290, United States
}

\begin{abstract}
How molecular conformation variation due to the existence of steric torsions within the conjugated backbones plays a role in molecular packing and resultant polymer solar cell (PSC) performance was investigated by synthesizing two isomeric alternating $\mathrm{D}-\mathrm{A}$ copolymers. In these copolymers, poly $\left\{3^{\prime}, 4^{\prime}\right.$ dihexyl-(2,2':5', $2^{\prime \prime}$-terthiophene $)-5,5^{\prime \prime}$-diyl-alt- $\left[4^{\prime}, 7^{\prime}\right.$-di-2-(4- $\left(2^{\prime}\right.$ ethylhexyl) )thienyl-( $5^{\prime}, 6^{\prime}$-difluorobenzo $[\mathrm{c}]\left[1^{\prime}, 2^{\prime}, 5^{\prime}\right]$ thiadiazole $\left.)\right]$ 5,5-diyl $\}$ (PTDTffBT $(\mathrm{C} 6 / \mathrm{EH})$ ) and poly $\left\{3^{\prime}, 4^{\prime}-\mathrm{di}\left(2^{\prime}\right.\right.$-ethylhexyl)$\left(2,2^{\prime}: 5^{\prime}, 2^{\prime \prime}\right.$-terthiophene $)-5,5^{\prime \prime}$-diyl-alt- $\left[4^{\prime}, 7^{\prime}\right.$-di-2-(4-hexyl) thien-

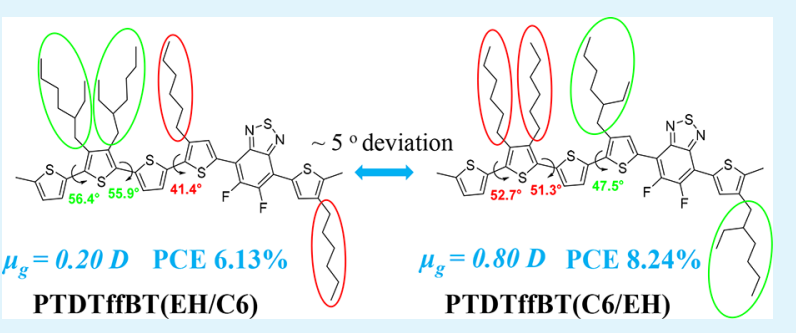
yl-(5',6'-difluorobenzo[c] $\left[1^{\prime}, 2^{\prime}, 5^{\prime}\right]$ thiadiazole) $]-5,5$-diyl $\}$ (PTDTffBT(EH/C6)), which had comparable molecular weight, the linear hexyl and branched 2-ethylhexyl chains are interchanged between the donor and the acceptor units. Such molecular design could offer two isomeric donors with limited conformational steric distortions by positioning the given alkyl chains with fine steric disparity in the same conjugated backbone. The interchange of the side chains caused a fluctuation of $\sim 5^{\circ}$ of the dihedral angles between the thiophenes within the donor units and between the ending thiophenes from the adjacent donor and acceptor units. The subtle transform on backbone steric distortions of the two copolymers leads to a negligible impact on electronic structures but a distinct one on molecular packing in film. The copolymers both embody polymorph molecular packing with preferential edge-on orientation in neat films. The (100) and (010) distance, corresponding to the lamellar stacking between the alkyl chains and the $\pi-\pi$ stacking between the conjugated backbones, are both improved in the PTDTffBT(C6/EH) film with enhanced crystallinity than that in the PEDTffBT(EH/C6) film. Similar molecular packing feature remains for the $\mathrm{BHJ}$ blends of the two copolymers with the acceptor of $\mathrm{PC}_{71} \mathrm{BM}$. Moreover, PTDTffBT(C6/EH) exhibits the apparant coexistence of face-on orientation with improved crystallinity. The PTDTffBT(C6/EH): PC ${ }_{71} B M$ PSC devices offer a much improved maximum power conversion efficiency (PCE) of $8.24 \%$ over $6.13 \%$ of the PTDTffBT(EH/C6) device, mainly due to more efficient charge generation and balanced charge transport resulted from the optimized film microstructure. The investigation clearly shows the sensitivity of molecular packing and corresponding PSC device performance to subtle steric distortions within conjugated backbones.
\end{abstract}

KEYWORDS: polymer solar cell, D-A copolymer, side-chain engineering, molecular conformation, morphology

\section{INTRODUCTION}

As a prospective technology for green and sustainable energy by photoelectric conversion, bulk heterojunction (BHJ) polymer solar cells (PSCs) have attracted considerable attention in recent years because of their advantages of low cost, light weight, large-area fabrication capability, and flexibility. ${ }^{1,2}$ It has been well-demonstrated that each single step within a photoelectric conversion process is strongly correlated with both the electronic structures of the materials employed and the morphological structure of the $\mathrm{BHJ}$ film for a specific PSC device. ${ }^{3-5}$ The superposed efforts, both from molecular engineering on optimizing the electronic and morphological structure of active materials and from interfacial engineering on devices, have become popular and indispensable plots in PSC research to push performance up forward. ${ }^{6-16}$ Owing to chemists by continuously feeding the area with remarkable active materials, the maximum power conversion efficiencies (PCE) of PSCs in a single junction have

Received: June 11, 2018

Accepted: July 30, 2018

Published: July 30, 2018 
been achieved up to $12 \%$ for polymer:fullerene blends, $9 \%$ for all-polymer blends, and $14 \%$ for polymer:nonfullerene small molecular acceptor blends. ${ }^{17-22}$

Polymer donors consisting alternating electron-donating (D) and electron-accepting (A) building blocks with variable strength represents one of the most powerful material sources because of its facile tunability on electronic structures. ${ }^{23}$ Molecular engineering on $\mathrm{D}-\mathrm{A}$ copolymers for efficient solution-processed $\mathrm{BHJ}$ solar cells have been unexceptionally carried out on constituting components of conjugated backbones, electron donating or withdrawing substituents and side chains, which often synergistically exert functions and cannot be solely explained by their own influences. Linear- and angular-shaped heteroacenes as well as ladder-type donor units have been widely explored as conjugated backbones as the primary factor in dictating the intrinsic electronic properties of resulted copolymers. The introduction of oligo thiophenes and/or $\pi$-extended heteroacenes with ending thiophenes as building blocks has been noticeably proved to offer efficient photovoltaic properties. ${ }^{24-27}$ Properly decorated side chains of a given D-A copolymer donor, such as alkyl, alkoxy, oligo(ethylene glycol), and even fluorinated chains, have been found to not only serve as solubilizing groups for easy processing but also play a critical role on its electronic and morphological features within the corresponding $\mathrm{BHJ}$ blend. ${ }^{28-32}$ Tremendous efforts on side chain engineering, for example, modifying the polarity, length, branch point, and position linked to the $\mathrm{D}$ and/or $\mathrm{A}$ units, have been paved out toward understanding their influence on photovoltaic properties and achieving high performance. ${ }^{33-41}$ The main argument is that structural rearrangement and intramolecular interactions occur by varying the position and nature of the side chains in D-A copolymers with a specific conjugated backbone; the corresponding optoelectronic, morphological, and photovoltaic properties of the copolymers also vary with these changes.

Given the premise that the solubility issue can be guaranteed, it is essential whether the electronic and morphological features of a D-A copolymer perturbed by structure variation satisfy the requirement for highly efficient photoelectric conversion procedures within the PSC device through molecular engineering on constituting conjugated backbones, substituents, and side chains. When engineering $\mathrm{D}-\mathrm{A}$ copolymers on these structural components, no matter what constitution is introduced as mentioned above, the molecular conformation of the final polymers varies accordingly. Assuming the structural perturbation resulted from molecular engineering mainly by tuning both the intrachain conformational structure and interchain interactions, we envision that the molecular conformational variation could be responsible as well for morphological evolution of $\mathrm{D}-\mathrm{A}$ copolymers and their corresponding PSC device performance. Despite above-mentioned ongoing progress, the impact of molecular conformational variation on both the morphological features and thereafter the performance of corresponding PSC device is not yet fully realized and understood in the case that the position and nature of the side chains are all set beforehand within a specific D-A copolymer. The most effective way to obtain such $\mathrm{D}-\mathrm{A}$ copolymers with varied stable molecular conformations would most likely have to be achieved through isomers bearing different steric torsions within their conjugated backbones.

The D-A copolymers with an A unit of 4,7-dithienyl-5,7difluobenzo[c] $][1,2,5]$ thiadizole (DTffBT) and a D unit of oligothiophene (T) have emerged as the most successful polymer donors enabling highly efficient PSCs. ${ }^{26}$ The PSC device performance has been found to be very sensitive to the size and the position of alkyl chains for blends of DTffBT based polymers and fullerene acceptors. ${ }^{17,42-44}$ To investigate how the molecular conformation variation due to the existence of steric torsions within the conjugated backbones plays the role on affecting molecular packing and corresponding PSC performance, herein, we well-designed two isomeric D-A copolymers via interchanging the alkyl side chains positioned on the donor and acceptor units using the platform of $\mathrm{D}-\mathrm{A}$ copolymers with the $\mathrm{D}$ unit of $3^{\prime}, 4^{\prime}$-dialkyl-2,2 $2^{\prime}: 5^{\prime}, 2^{\prime \prime}$ terthiophene $(\mathrm{T})$ and the acceptor unit of 4,7-bis(4-(2alkyl)thiophen-2-yl)-5,6-difluorobenzo[c] [1,2,5] thiadiazole (DTffBT). The alkyl chains of hexyl and 2-ethylhexyl were incorporated at the positions as indicated in $\mathrm{T}$ and DTffBT units, respectively, affording two isomeric $\mathrm{D}-\mathrm{A}$ copolymers of poly $\left\{3^{\prime}, 4^{\prime}\right.$-dihexyl- $\left(2,2^{\prime}: 5^{\prime}, 2^{\prime \prime}\right.$-terthiophene $)-5,5^{\prime \prime}$-diyl-alt$\left[4^{\prime}, 7^{\prime}\right.$-di-2-(4-(2' -ethylhexyl))thienyl- $\left(5^{\prime}, 6^{\prime}\right.$-difluorobenzo[c]$\left[1^{\prime}, 2^{\prime}, 5^{\prime}\right]$ thiadiazole) $]-5,5-$ diyl $\}$ (PTDTffBT $(\mathrm{C} 6 / \mathrm{EH})$ ) and poly $\left\{3^{\prime}, 4^{\prime}-\operatorname{di}\left(2^{\prime}\right.\right.$-ethylhexyl $)-\left(2,2^{\prime}: 5^{\prime}, 2^{\prime \prime}\right.$-terthiophene $)-5,5^{\prime \prime}$ diyl-alt- $\left[4^{\prime}, 7^{\prime}\right.$-di-2-(4-hexyl)thienyl- $\left(5^{\prime}, 6^{\prime}\right.$-difluorobenzo[c]$\left[1^{\prime}, 2^{\prime}, 5^{\prime}\right]$ thiadiazole) $]-5,5$-diyl $\}$ (PTDTffBT(EH/C6)). Taking advantage of the fine disparity of the steric effect between the linear hexyl and the branched 2-ethylhexyl chains in conjugation with their fixed anchor position on the donor and acceptor units, we can create a subtle steric distortion variation along the whole conjugated backbone between the two copolymers. A fluctuation around $5^{\circ}$ of dihedral angles are obtained between the thiophenes within the donor units and between the ending thiophenes from the adjacent donor and acceptor units by DFT calculations. This gentle molecular conformation variation of the two copolymers impacts barely on their electronic structures but distinctly on molecular packing both in neat films and in the $\mathrm{BHJ}$ blends with the acceptor of $\mathrm{PC}_{71} \mathrm{BM}$. The PTDTffBT $(\mathrm{C} 6 / \mathrm{EH}): \mathrm{PC}_{71} \mathrm{BM}$ polymer solar cell (PSC) device enables a much improved maximum PCE of $8.24 \%$ over $6.13 \%$ from the PTDTffBT $(\mathrm{EH} /$ C6) device.

\section{EXPERIMENTAL SECTION}

General information on materials, device fabrication, and characterizations can be found in the Supporting Information.

Synthesis of Poly $\left\{3^{\prime}, 4^{\prime}\right.$-dihexyl- $\left(2,2^{\prime}: 5^{\prime}, 2^{\prime \prime}\right.$-terthiophene)-

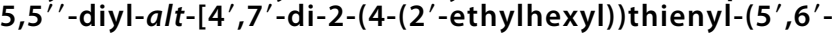
difluorobenzo[c][1 $1^{\prime}, 2^{\prime}, 5^{\prime}$ ]thiadiazole)]-5,5-diyl\} (PTDTffBT(C6/ $\mathrm{EH})$ ). Into a $50 \mathrm{~mL}$ round-bottom flask was added 4,7-bis(5-bromo-4(2-ethylhexyl)thiophen-2-yl)-5,6-difluorobenzo[c] $[1,2,5]$ thiadiazole

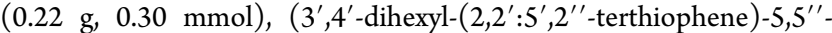
diyl)bis(trimethylstannane) $(0.22 \mathrm{~g}, 0.30 \mathrm{mmol})$. The flask was then transferred to a glovebox where $\operatorname{Pd}_{2}(\mathrm{dba})_{3}(8.24 \mathrm{mg}, 0.009 \mathrm{mmol})$, tri(o-tolyl)phosphine $(16.42 \mathrm{mg}, 0.054 \mathrm{mmol})$ and $8.0 \mathrm{~mL}$ of anhydrous chlorobenzene were added under nitrogen. After being transferred out of the glovebox, the round-bottom flask was heated at reflux for $48 \mathrm{~h}$ under the protection of $\mathrm{N}_{2}$. The reaction mixture was then added dropwise into $100 \mathrm{~mL}$ of methanol at room temperature. The precipitate was collected by filtration and extracted by a Soxhlet apparatus with acetone, hexane, dichloromethane and chloroform sequentially. The chloroform fraction was then concentrated via rotavap evaporation and precipitated in methanol. The solid was filtered and dried under vacuum to offer the final product $(135 \mathrm{mg}$, yield $46.5 \%)$. Resolvable ${ }^{1} \mathrm{H}$ NMR spectrum of PTDTffBT(C6/EH) was unable to be obtained due to its strong aggregation in $\mathrm{CDCl}_{3}$.

Synthesis of Poly\{ $\left\{3^{\prime}, 4^{\prime}-\operatorname{di}\left(2^{\prime}\right.\right.$-ethylhexyl $)-\left(2,2^{\prime}: 5^{\prime}, 2^{\prime \prime}\right.$-terthiophene)-5, $5^{\prime \prime}$-diyl-alt-[ $4^{\prime}, 7^{\prime}$-di-2-(4-hexyl)thienyl- $\left(5^{\prime}, 6^{\prime}\right.$ difluorobenzo[c][1 $1^{\prime}, 2^{\prime}, 5^{\prime}$ ]thiadiazole)]-5,5-diyl\} (PTDTffBT(EH/ 
Scheme 1. Synthesis of the Copolymers

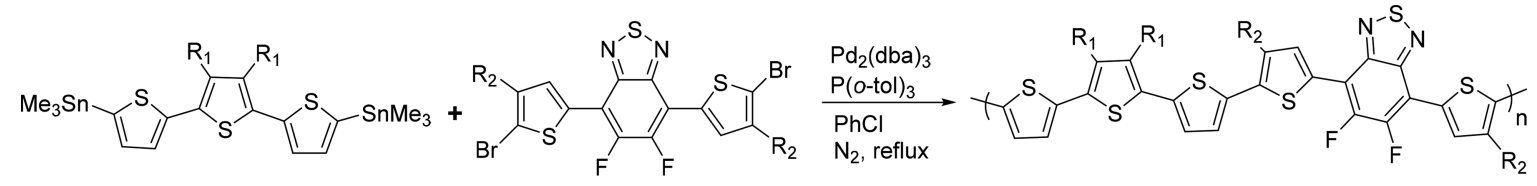

PTDTffBT(EH/C6), $R_{1}=$ 2-ethylhexyl, $R_{2}=$ hexyl PTDTffBT(C6/EH), $R_{1}=$ hexyl, $R_{2}=$ 2-ethylhexyl



Figure 1. Torsion angles caused by side chains and frontier orbital distribution of TDTffBT(EH/C6) and TDTffBT(C6/EH) calculated at the level of B3LYP/6-311G(d) level of density functional theory.

C6)). The polymer was synthesized according to the similar procedure for PTDTffBT(C6/EH) from 4,7-bis(5-bromo-4-hexylthiophen-2yl)-5,6-difluorobenzo[c] $[1,2,5]$ thiadiazole $(0.20 \mathrm{~g}, 0.30 \mathrm{mmol})$ and ( $3^{\prime}, 4^{\prime}$-bis (2-ethylhexyl)-(2,2': $5^{\prime}, 2^{\prime \prime}$-terthiophene)-5, $5^{\prime \prime}$-diyl)-bis(trimethylstannane) $(0.24 \mathrm{~g}, 0.30 \mathrm{mmol})$ and $115 \mathrm{mg}$ of the final product was obtained from the chloroform fraction after Soxhlet extraction with a yield of $40.5 \%$. Resolvable ${ }^{1} \mathrm{H}$ NMR spectrum of $\mathrm{PTDTffBT}(\mathrm{EH} / \mathrm{C} 6)$ was unable to be obtained in $\mathrm{CDCl}_{3}$, as similarly happened for PTDTffBT(C6/EH).

\section{RESULTS AND DISCUSSION}

3.1. Synthesis and Characterization. The synthesis of the target $\mathrm{D}-\mathrm{A}$ copolymers are presented in Scheme 1 . The corresponding monomers of $\left(3^{\prime}, 4^{\prime}\right.$-dialkyl- $\left(2,2^{\prime}: 5^{\prime}, 2^{\prime \prime}\right.$-terthiophene)-5,5'-diyl)-bis(trimethylstannane) $(\mathrm{T})$ and 4,7-di(5bromo-4-alkylthiophen-2-yl)-5,6-difluoro-benzo[c][1,2,5]thiadiazole (DTffBT) were prepared as described in the Supporting Information. The copolymers were then synthesized via Stille cross-coupling reaction using chlorobenzene as the solvent and tris(dibenzylideneacetone)dipalladium $\left(\mathrm{Pd}_{2}(\mathrm{dba})_{3}\right)$ and tri(o-tolyl)-phosphine $\left(\mathrm{P}(o-\mathrm{Tol})_{3}\right)$ as the catalyst. Both copolymers showed good solubility in common organic solvents such as chloroform and $o$-dichlorobenzene $(o-$ DCB). The number-average molecular weights of PTDTffBT(EH/C6) and PTDTffBT(C6/EH) are 14.1 and $12.2 \mathrm{kDa}$, with the polydispersity index (PDI) of 1.8 and 1.6, respectively, as measured by gel permeation chromatography (GPC) in trichlorobenzene at $150{ }^{\circ} \mathrm{C}$ against polystyrene standards. It is worth noting that the number-average molecular weights of two copolymers are comparable, which minimizes the effects of molecular weight on the various properties of resulted polymers. The thermal properties of the copolymers were investigated using thermogravimetric analysis (TGA) under nitrogen. Both of the copolymers exhibited good thermal stability with the decomposition temperature (defined as the $5 \%$ weight-loss temperature, $T_{\mathrm{d}}$ ) over $430{ }^{\circ} \mathrm{C}$ (Figure S25).

3.2. Theoretical Calculations and Optical and Electrochemical Properties. To explore the effect of side chain interchanging between the donor of $3^{\prime}, 4^{\prime}$-dialkyl-2,2 $2^{\prime}: 5^{\prime}, 2^{\prime \prime}$ terthiophene $(\mathrm{T})$ and the acceptor unit of (4-alkylthiophen-2yl)-5,6-difluoro-benzo[c] $[1,2,5]$ thiadiazole (DTffBT) on polymer properties, the dihedral angles between the thiophenes within the donor unit and between the ending thiophenes from the adjacent donor and acceptor units, and frontier orbital distribution of corresponding two model compounds (TDffBT(EH/C6) and TDffBT(C6/EH) as presented in Figure 1 were calculated using density functional theory (DFT). The hexyl and 2-ethylhexyl groups remained for the calculation to objectively reflect the subtle structure con- 
formation deviation caused by the interchanging of alkyl side chains. As shown in Figure 1, at the minimum energy state, the dihedral angles of $\sim 56^{\circ}$ between the thiophenes within the terthiophene unit and $\sim 41^{\circ}$ between the ending thiophenes from the adjacent donor of terthiophene and the acceptor of DTffBT were obtained in TDffBT(EH/C6). In TDffBT(C6/ $\mathrm{EH})$, nevertheless, the dihedral angles of $\sim 52^{\circ}$ within the terthiophene unit and $\sim 47^{\circ}$ between the donor and acceptor unit were obtained. Positioning branched 2-ethylhexyl chains results in an increase around $5^{\circ}$ of the dihedral angles either on the donor unit or the acceptor units while it is on the contrary for linear hexyls. Such subtle dihedral angle fluctuations causes little variation on electronic communication between the donor and acceptor unit for the two model compounds due to their similar electron cloud distributions at frontier molecular orbitals and very close energy levels as depicted in Figure 1. However, TDTffBT $(\mathrm{C6} / \mathrm{EH})$ has a higher ground state dipole moment of $0.80 \mathrm{D}$ than that of $0.20 \mathrm{D}$ in TDTffBT(EH/C6) (Figure S26), suggesting that PTDTffBT $(\mathrm{C6} / \mathrm{EH})$ could be expected to exhibit a more closed packing structure because higher dipole moment can help to enhance molecular interactions. ${ }^{45-47}$

The temperature-dependent UV-vis absorption spectra of the two copolymers in diluted $o$-DCB solution with the concentration of $1 \times 10^{-5} \mathrm{~g} \mathrm{~mL}^{-1}$ are presented in Figure S27. As can be seen from Figure S27a, PTDTffBT(EH/C6) is well dissolved over $90^{\circ} \mathrm{C}$ and a bathochromic shift of $\sim 12 \mathrm{~nm}$ can be observed for the maximum absorption wavelength $\left(\lambda_{\text {max,sol }}\right)$ at $\sim 526 \mathrm{~nm}$ when the temperature decreases from $100{ }^{\circ} \mathrm{C}$ to room temperature. PTDTffBT $(\mathrm{C} 6 / \mathrm{EH})$ is found to be similarly well dissolved at elevated temperature over $90{ }^{\circ} \mathrm{C}$ with the $\lambda_{\text {max,sol }}$ at $\sim 533 \mathrm{~nm}$ with a bathochromic shift of $\sim 7$ $\mathrm{nm}$ to that of PTDTffBT(EH/C6), indicative of a slight impact on spectral tuning by interchanging the alkyl side chain of hexyl and 2-ethylhexyl on the terthiophene unit and the DTffBT unit. As the temperature decreases from $100{ }^{\circ} \mathrm{C}$ to room temperature, the $\lambda_{\text {max,sol }}$ moves to $\sim 538 \mathrm{~nm}$ with a slight bathchromic shift of around $5 \mathrm{~nm}$. Such slight variations of the $\lambda_{\text {max }, \text { sol }}$ of the two copolymers suggests no obvious temperature dependent aggregation existed as observed from the literatues. The absorption spectra of the two copolymers in the diluted solutions at $100{ }^{\circ} \mathrm{C}$ and in thin film at room temperature are thus compiled in Figure 2. Both copolymers exhibit characteristic dual absorption bands in solution as observed for a typical

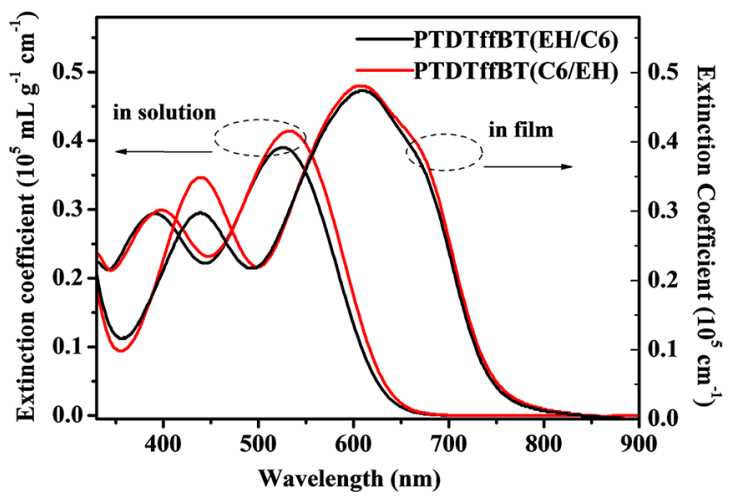

Figure 2. UV-vis absorption spectra of PTDTffBT(EH/C6) and PTDTffBT $(\mathrm{C} 6 / \mathrm{EH})$ in $o-\mathrm{DCB}$ solution at $100{ }^{\circ} \mathrm{C}$ and in neat thin films as cast from $o$-DCB solutions $\left(10 \mathrm{mg} \mathrm{mL}^{-1}\right)$ at room temperature.
D-A alternating copolymer, where the high-energy one ( $\sim 395$ $\mathrm{nm})$ is originated from the $\pi-\pi^{*}$ transition and the low-energy one $(\sim 530 \mathrm{~nm})$ is assigned to the intramolecular charge transfer transition from the donor to the acceptor units. For thin films as cast from the $o$-DCB solution, PTDTffBT $(\mathrm{EH} /$ C6) and PTDTffBT(C6/EH) exhibit an absorption maxima $\left(\lambda_{\max }\right.$ film, Table 1$)$ at 606 and $612 \mathrm{~nm}$, respectively, both redshifted by around $80 \mathrm{~nm}$ when compared with those of corresponding solutions. The films of the two copolymers show a vibronic shoulder peak at around $665 \mathrm{~nm}$. Moreover, the shoulder peak of PTDTffBT $(\mathrm{C} 6 / \mathrm{EH})$ is a little bit stronger than that of PTDTffBT(EH/C6), suggesting its more prominent interchain aggregation through effective $\pi-\pi$ stacking in film. It needs to be noted that PTDTffBT $(\mathrm{C} 6 / \mathrm{EH})$ shows gently higher extinction coefficients along most of the visible region both in solution and in film, which seems to play a positive role on the absorption capability of corresponding PSC device as can be observed lately from the device characterization.

From the absorption onset, the optical band gaps ( $E_{\mathrm{g}, \mathrm{opt}}$, Table 1) of PTDTffBT(EH/C6) and PTDTffBT(C6/EH) were estimated to be 1.68 and $1.67 \mathrm{eV}$, respectively. The energy levels of both copolymers were further measured by cyclic voltammetry $(\mathrm{CV})$ of thin films as depicted in Figure S28. The HOMO energy levels of PTDTffBT(EH/C6) and PTDTffBT $(\mathrm{C6} / \mathrm{EH})$ were determined to locate at -5.28 and $-5.23 \mathrm{eV}$ calculated from the onset oxidation potentials $\left(E_{\mathrm{ox}}\right)$ and the LUMO energy levels at -3.60 and $-3.56 \mathrm{eV}$ respectively from the formula of $E_{\mathrm{LUMO}}=E_{\mathrm{HOMO}}+E_{\mathrm{g} \text {, opt }}$. The gap between the HOMOs and LUMOs of the two copolymers was rather smaller than $0.05 \mathrm{eV}$, indicative of the negligible effect of switching the alkyl chains between the donor and acceptor units on the electronic structure of the resulting copolymers. All optical and electrochemical parameters of the copolymers are tabulated in Table 1.

3.3. Photovoltaic Properties. PSC devices with conventional device configuration of ITO/PEDOT:PSS/polymer: $\mathrm{PC}_{71} \mathrm{BM} / \mathrm{Ca} / \mathrm{Al}$ were fabricated to evaluate the photovoltaic performance of the two copolymers. The energy levels of the polymer donors and the acceptor of $\mathrm{PC}_{71} \mathrm{BM}$ are presented in Figure S29 in conjugation with the other electronic materials within the devices. The active layers were spin-coated from the polymer: $\mathrm{PC}_{71} \mathrm{BM}$ solutions in $o$ $\mathrm{DCB}$ with the polymer concentration of $10 \mathrm{mg} \mathrm{mL}^{-1}$. The optimal weight ratio of polymer: $\mathrm{PC}_{71} \mathrm{BM}$ was found to be $1: 1$ (Table S1) for the two copolymers. The film thickness of optimized devices was $102 \mathrm{~nm}$ for the PTDTffBT(EH/ C6): $\mathrm{PC}_{71} \mathrm{BM}$ blend and $106 \mathrm{~nm}$ for the PTDTffBT(C6/ $\mathrm{EH}): \mathrm{PC}_{71} \mathrm{BM}$ blend. Varied amounts of processing additives such as diphenyl ether (DPE), 1,8-diiodooctane (DIO) and 1chloronaphthalene $(\mathrm{CN})$ for the $\mathrm{BHJ}$ films were tried as well only to find that none of them worked positively (Table S2), suggesting that the solvent additives did harm to the morphology evolution of the $\mathrm{BHJ}$ films during casting. Figure 3 a presents the typical current-voltage $(J-V)$ characteristics of the optimized BHJ PSCs under simulated AM 1.5G solar illumination while the detailed photovoltaic parameters are listed in Table 2. The highest PCE was found to be $8.24 \%$ for the PTDTffBT(C6/EH):PC 71 BM blend, with an open circuit voltage $\left(V_{\mathrm{oc}}\right)$ of $0.789 \mathrm{~V}$, a short-circuit current density $\left(J_{\mathrm{sc}}\right)$ of $17.36 \mathrm{~mA} \mathrm{~cm}$, and an fill factor (FF) of 0.60. Lower photovoltaic performance was found for the PTDTffBT $(\mathrm{EH} /$ C6): $\mathrm{PC}_{71} \mathrm{BM}$ blend with the highest PCE of $6.13 \%$ due to the 
Table 1. Optical and Electrochemical Parameters of the Copolymers

\begin{tabular}{cccccccc} 
polymer & $\lambda_{\max \text { sol }}(\mathrm{nm})$ & $\lambda_{\max \text { film }}(\mathrm{nm})$ & $\lambda_{\text {film onset }}(\mathrm{nm})$ & $E_{\text {g,opt }}{ }^{a}(\mathrm{eV})$ & $E_{\text {ox }}(\mathrm{V})$ & $E_{\text {HOMO }}(\mathrm{eV})$ & $E_{\mathrm{LUMO}}{ }^{c}(\mathrm{eV})$ \\
\hline PTDTffBT $(\mathrm{EH} / \mathrm{C} 6)$ & 526 & 606,665 & 741 & 1.68 & 0.48 & -5.28 & -3.60 \\
PTDTffBT $(\mathrm{C} 6 / \mathrm{EH})$ & 533 & 612,665 & 745 & 1.67 & 0.43 & -5.23 & -3.56
\end{tabular}

${ }^{a}$ Calculated from the onset of the electronic absorption of the polymer films $\left(E_{\mathrm{g}}{ }^{\mathrm{ptt}}=1240 / \lambda(\mathrm{nm})\right) .{ }^{b}$ Estimated from the oxidation onset vs $\mathrm{Fc} / \mathrm{Fc}^{+}$ by the equation of $E_{\mathrm{HOMO}}=-4.8-E^{\mathrm{ox}}{ }_{\text {onset }}{ }^{c}$ Estimated by the equation of $E_{\mathrm{LUMO}}=E_{\mathrm{HOMO}}+E_{\mathrm{g} \text {, opt }}$
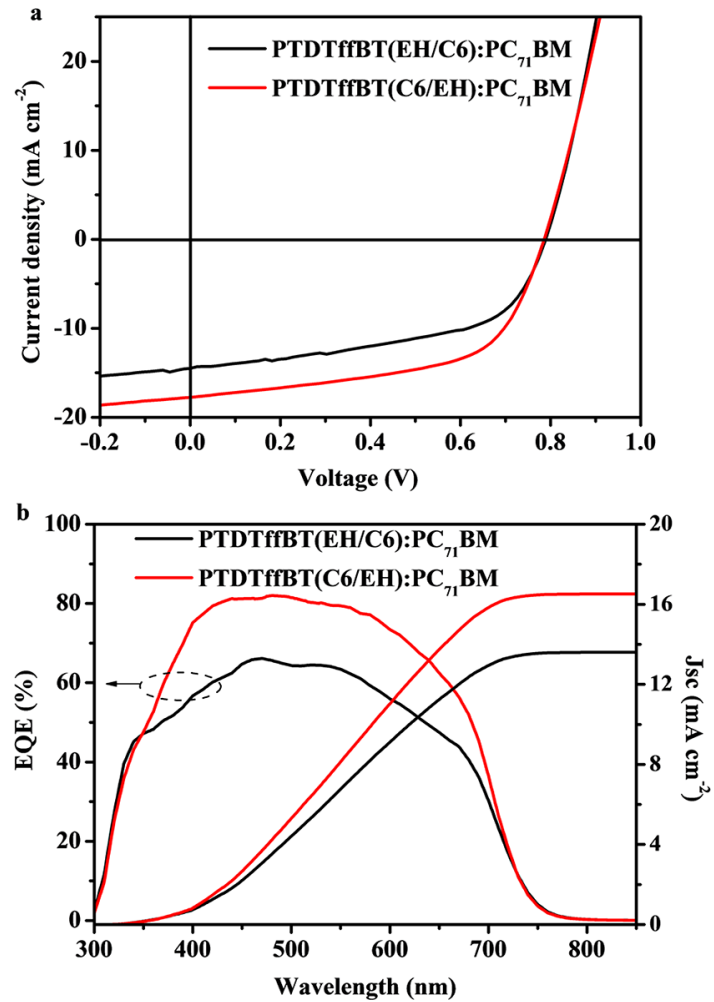

Figure 3. (a) Typical $J-V$ curves of the optimized PSCs with PTDTffBT(EH/C6):PC ${ }_{71} \mathrm{BM}$ and PTDTffBT(C6/EH):PC ${ }_{71} \mathrm{BM}$ blends in conventional device configuration and (b) their corresponding EQE spectra.

smaller $J_{\mathrm{sc}}\left(14.63 \mathrm{~mA} \mathrm{~cm}^{-2}\right)$ and FF (0.53). It should be noted that both $\mathrm{BHJ}$ blends exhibit similar $V_{\mathrm{oc}}$ values, which can be ascribed to the negligible difference on their HOMO energy levels as mentioned above. The short-circuit current densities calculated from the external quantum efficiency (EQE) spectra (Figure $3 b$ ) matched well with the divergence in the direct $J-$ $V$ measurements under simulated AM 1.5 G solar illumination. It is obvious that the main absorption from 350 to $700 \mathrm{~nm}$ of the two copolymers contribute to the photocurrent generation. The maximum EQE value of the PTDTffBT(C6/ $\mathrm{EH}): \mathrm{PC}_{71} \mathrm{BM}$ blend reaches close to 0.8 whereas it is only close to 0.65 for PTDTffBT(EH/C6) within the strongest absorption range of the $\mathrm{BHJ}$ films. As depicted in Figure S30, the optimized PTDTffBT(C6/EH): $\mathrm{PC}_{71} \mathrm{BM}$ blend offers stronger light absorption capability than that of the blend of PTDTffBT(EH/C6):PC ${ }_{71} \mathrm{BM}$ because of slightly higher absorption extinction coefficients along the most part of visible region and thicker film thickness, which partially accounts for the higher $J_{\text {sc }}$ value of the PTDTffBT(C6/ $\mathrm{EH}): \mathrm{PC}_{71} \mathrm{BM} \mathrm{BHJ}$ PSC device. Given the comparable energy levels and the seemingly optimized device conditions, it becomes clear that the observed large difference on the $J_{\mathrm{sc}}$ and FF upon switching the side chains between the donor and acceptor moieties of both copolymers could be mainly related to the factors involved in determining the efficiencies of exciton diffusion and dissociation, charge transport and recombination, and charge collection within the BHJ films.

3.4. Exciton Generation, Dissociation, Charge Transport, and Recombination. The superior performance of the PTDTffBT(C6/EH):PC ${ }_{71} \mathrm{BM}$ blend over that of PTDTffBT$(\mathrm{C} 6 / \mathrm{EH}): \mathrm{PC}_{71} \mathrm{BM}$ predominantly benefits from the greater contribution of the higher $J_{\mathrm{sc}}(18 \%$ increase) and FF $(13 \%$ increase). Practically, each step within a light-to-electricity conversion process from photon absorption to charge collection in a PSC device conceals potential energy loss mechanisms to deteriorate the overall PCE. The excitons initially generated by light absorption have to diffuse to the donor/acceptor interfaces and dissociate further to form free charge carriers as akin as to photoluminescence quenching. To evaluate the efficiency of exciton generation and dissociation, static fluorescence spectroscopy testing was thus carried out on both the neat polymer and the $\mathrm{BHJ}$ blend films as shown in Figure 4a. The excitation wavelength of $650 \mathrm{~nm}$ was chosen for both copolymers according to their absorption spectra. Relative to the neat polymer film, the photoluminescence of PTDTffBT(C6/EH) appears to be significantly quenched in the PTDTffBT(C6/EH):PC ${ }_{71} \mathrm{BM}$ blend by up to $92 \%$. However, the photoluminescence of PTDTffBT $(\mathrm{EH} / \mathrm{C} 6)$ is quenched only by $84 \%$ in the PTDTffBT(EH/C6):PC ${ }_{71} \mathrm{BM}$ blend. This indicates that the electron transfer process proceeds more efficiently within the PTDTffBT(C6/ $\mathrm{EH}): \mathrm{PC}_{71} \mathrm{BM}$ blend. The trend of photoluminescence quenching of the copolymers within the corresponding $\mathrm{BHJ}$ blends is greatly in agreement with the obtained discrepancy in the $J_{\text {sc }}$ values under AM $1.5 \mathrm{G}$ irradiation.

Depicted in Figure $4 \mathrm{~b}$ are the plots of the photocurrent density $\left(J_{\mathrm{ph}}\right)$ as a function of the internal voltage $\left(V_{\text {eff }}\right)$ of the two devices, which reveal how the $J_{\mathrm{ph}}$ responded to the $V_{\text {eff }}$ of the devices composed of the two copolymers. In this case, $J_{\mathrm{ph}}=$ $J_{\mathrm{L}}-J_{\mathrm{D}}$, where $J_{\mathrm{L}}$ and $J_{\mathrm{D}}$ are the current density under incident light and in dark, respectively, and $V_{\text {eff }}=V_{\mathrm{bi}}-V_{\mathrm{app}}$, where $V_{\mathrm{bi}}$ is the built-in voltage when $J_{\mathrm{ph}}=0$ and $V_{\mathrm{app}}$ is the applied voltage. It is observed that the $J_{\mathrm{ph}}$ tends to saturate (defined as

Table 2. Optimized Maximum Photovoltaic Parameters of the Prepared PSCs with Parenthesized Averages and Standard Deviations Derived from 20 PSCs

$\begin{array}{lcccccc}\text { donor in BHJ blend } & V_{\mathrm{oc}}(\mathrm{V}) & J_{\mathrm{sc}}\left(\mathrm{mA} \mathrm{cm}^{-2}\right) & \mathrm{FF} \% & \mathrm{PCE} \text { max }(\%) & \mu_{\mathrm{h}}\left(\mathrm{cm}^{2} \mathrm{~V}^{-1} \mathrm{~s}^{-1}\right) & \mu_{\mathrm{e}}\left(\mathrm{cm}^{2} \mathrm{~V}^{-1} \mathrm{~s}^{-1}\right) \\ \text { PTDTffBT(EH/C6) } & 0.793(0.787 \pm 0.007) & 14.63(14.48 \pm 0.23) & 53.4(52.6 \pm 0.9) & 6.13(6.04 \pm 0.13) & 2.11 \times 10^{-4} & 1.34 \times 10^{-4} \\ \text { PTDTffBT(C6/EH) } & 0.789(0.786 \pm 0.005) & 17.36(17.19 \pm 0.21) & 60.2(59.3 \pm 1.3) & 8.24(8.10 \pm 0.19) & 6.54 \times 10^{-4} & 5.11 \times 10^{-4}\end{array}$



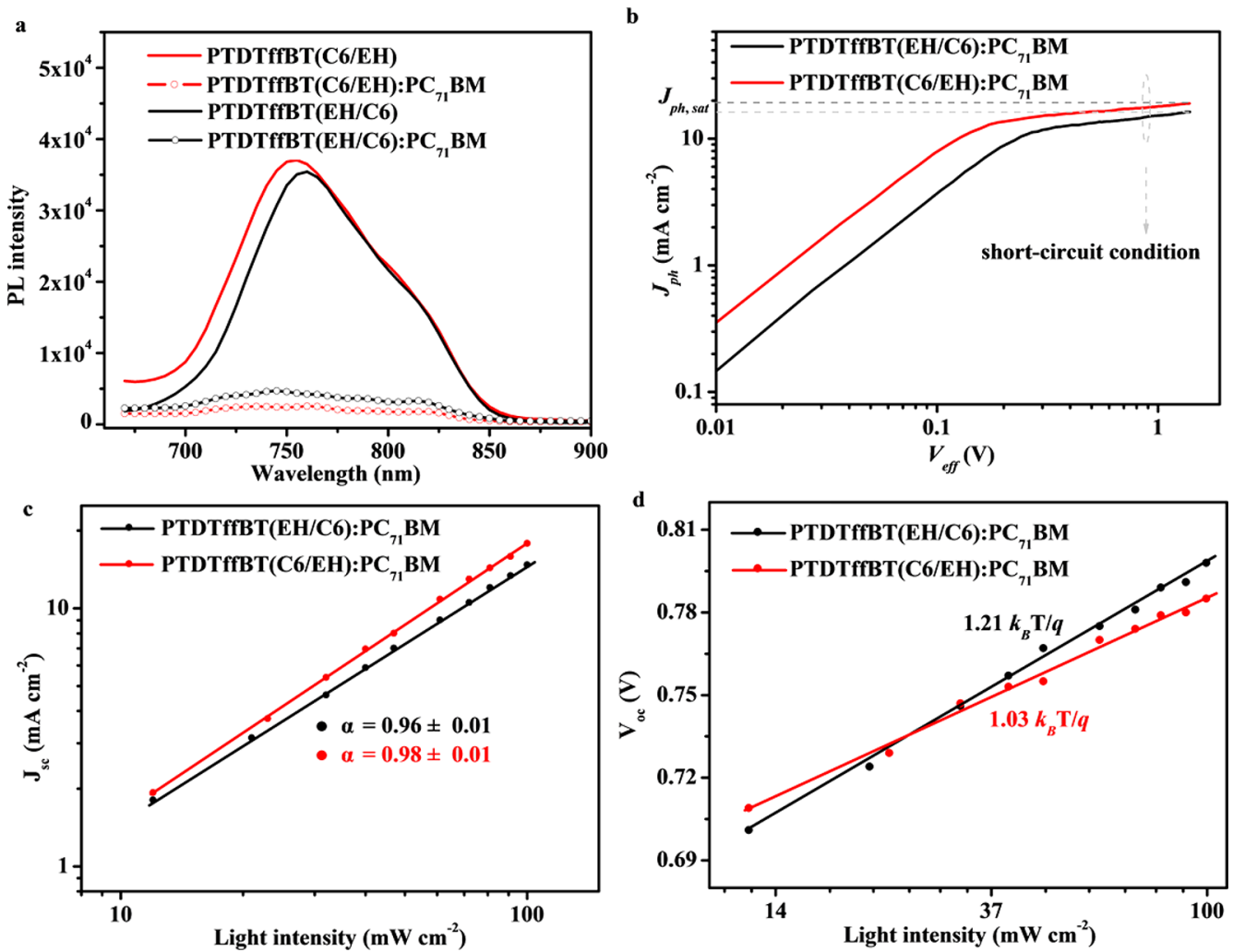

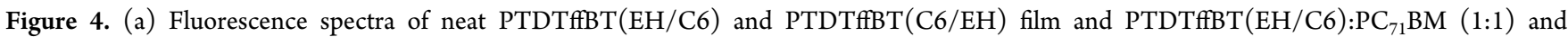
PTDTffBT(C6/EH):PC ${ }_{71} \mathrm{BM}$ (1:1) BHJ film excited at the wavelength of $650 \mathrm{~nm}$; b) $J_{\mathrm{ph}}-V_{\text {eff }}$ curves; (c) $J_{\text {sc }}$ and (d) $V_{\text {oc }}$ dependence on light intensity of the BHJ solar cell devices with PTDTffBT (EH/C6) and PTDTffBT(C6/EH), respectively.

the saturated photocurrent density, $\left.J_{\text {ph,sat }}\right)$ as $V_{\text {eff }}$ is close to $1 \mathrm{~V}$ and thus the maximum photoinduced charge carrier generation rate $\left(G_{\max }\right)$ of the devices can be calculated using the equation $J_{\mathrm{ph}, \mathrm{sat}}=q L G_{\max }$, where $q$ is the elementary charge and $L$ is the thickness of the $\mathrm{BHJ}$ layer. ${ }^{48-50}$ The $J_{\mathrm{ph} \text {, sat }}$ value is determined to be $16.5 \mathrm{~mA} \mathrm{~cm}{ }^{-2}$ for the PTDTffBT(EH/C6):PC ${ }_{71} \mathrm{BM}$ blend and $19.1 \mathrm{~mA} \mathrm{~cm}^{-2}$ for the PTDTffBT(C6/EH):PC ${ }_{71} \mathrm{BM}$ blend, whereas the value of $G_{\max }$ is accordingly calculated to be $1.01 \times 10^{28} \mathrm{~m}^{-3} \mathrm{~s}^{-1}$ and $1.12 \times 10^{28} \mathrm{~m}^{-3} \mathrm{~s}^{-1}$, respectively. The $G_{\max }$ of the device with PTDTffBT(C6/EH) increases nearly $12 \%$, indicating more photogenerated excitons and dissociated charge carriers offered in accordance with the photoluminescence quenching results.

Space-charge-limited current (SCLC) measurements were performed to investigate the vertical hole $\left(\mu_{h}\right)$ and electron $\left(\mu_{\mathrm{e}}\right)$ mobility of the two BHJ blend films (Figure S31). The hole- and electron-only devices were fabricated in the configuration of ITO/PEDOT:PSS $(40 \mathrm{~nm}) /$ polymers: $\mathrm{PC}_{71} \mathrm{BM} / \mathrm{MoO}_{3} / \mathrm{Ag}$ and $\mathrm{ITO} / \mathrm{ZnO}(30 \mathrm{~nm}) /$ polymers: $\mathrm{PC}_{71} \mathrm{BM} / \mathrm{Ca} / \mathrm{Al}$, respectively. The measured $\mu_{\mathrm{h}}$ and $\mu_{\mathrm{e}}$ value of the PTDTffBT(EH/C6):PC ${ }_{71} \mathrm{BM}$ blend is determined to be $2.11 \times 10^{-4}$ and $1.34 \times 10^{-4} \mathrm{~cm}^{2} \mathrm{~V}^{-1} \mathrm{~s}^{-1}$, with a $\mu_{\mathrm{h}} / \mu_{\mathrm{e}}$ value of 1.57. Nevertheless, the PTDTffBT(C6/EH):PC $\mathrm{PC}_{71} \mathrm{BM}$ blend exhibits a $\mu_{\mathrm{h}}$ of $6.54 \times 10^{-4} \mathrm{~cm}^{2} \mathrm{~V}^{-1} \mathrm{~s}^{-1}$ and a $\mu_{\mathrm{e}}$ of 5.11 $\times 10^{-4} \mathrm{~cm}^{2} \mathrm{~V}^{-1} \mathrm{~s}^{-1}$, both increased by more than three times leading to a $\mu_{\mathrm{h}} / \mu_{\mathrm{e}}$ value of 1.28 . The charge transport balance $\left(\mu_{\mathrm{h}} / \mu_{\mathrm{e}}\right)$ between the hole and electron mobility within a $\mathrm{BHJ}$ blend is important for improving the value of $J_{\mathrm{sc}}$ and FF for a PSC. The higher and more balanced hole and electron mobility in the PTDTffBT $(\mathrm{C} 6 / \mathrm{EH}): \mathrm{PC}_{71} \mathrm{BM}$ blend would help to reduce the steady state carrier density and suppressing photocurrent loss from charge recombination to enhance the $J_{\text {sc }}$ and FF.

The dependency of the device performances such as $J_{\mathrm{sc}}$ and $V_{\text {oc }}$ on the incident light intensity were investigated as well to identify the charge recombination state within the optimized devices. $^{25,49}$ According to the equation of $J_{\text {sc }} \propto \mathrm{P}_{\text {light }}^{\alpha}$, where $P_{\text {light }}$ is the light intensity, $\alpha$ should approach to the unity when the bimolecular recombination is negligible. As shown in Figure $4 c$, the fitted slopes $(\alpha)$ of the optimized devices are calculated to be 0.96 and 0.98 for the $\mathrm{BHJ}$ blend with PTDTffBT $(\mathrm{EH} / \mathrm{C} 6)$ and PTDTffBT $(\mathrm{C} 6 / \mathrm{EH})$, respectively. This indicates that the bimolecular recombination was suppressed more efficiently at short-circuit condition in the PTDTffBT(C6/EH): $\mathrm{PC}_{71} \mathrm{BM}$ blend. The state of the monomolecular recombination at the open circuit condition of a PSC device can be illustrated through the equation of $V_{\text {oc }} \propto$ $\left(n k_{B} T / q\right) \ln \left(P_{\text {light }}\right)$, where $k_{\mathrm{B}}$ is the Boltzmann constant, $T$ is temperature in Kelvin, and $q$ is the elementary charge. Generally, the involvement of the monomolecular recombination and its competition with the bimolecular recombination would lead to an increased $n$ beyond 1 . Relevant curves of $V_{\text {oc }}$ versus $P_{\text {light }}$ are therefore examined and presented in Figure $4 \mathrm{~d}$. The strongest dependence of $V_{\text {oc }}$ on the light intensity within the two devices provides a slope of $1.21 k_{\mathrm{B}} \mathrm{T} / q$ for the PTDTffBT(EH/C6): $\mathrm{PC}_{71} \mathrm{BM}$ blend with an $n$ value of 1.21 and $1.03 k_{\mathrm{B}} \mathrm{T} / q$ for the PTDTffBT $(\mathrm{C} 6 / \mathrm{EH}): \mathrm{PC}_{71} \mathrm{BM}$ blend with an $n$ value of 1.03, suggesting the least involvement of the monomolecular recombination under the open-circuit condition for the latter. The lower bimolecular recombination and significantly suppressed monomoelcular recombination is consistent with the more efficient charge transport estimated 

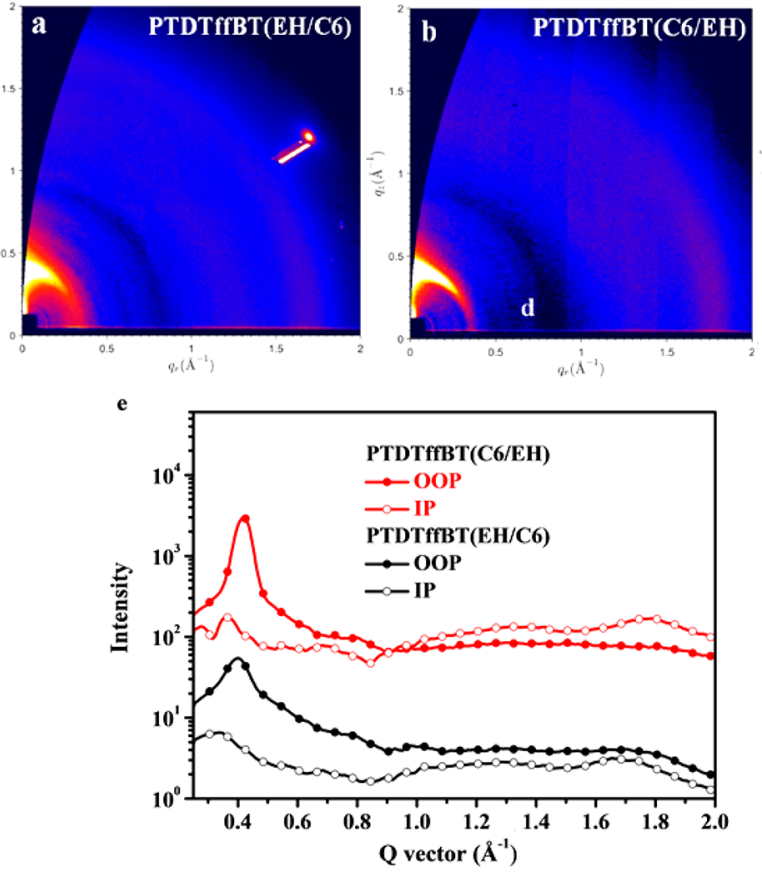
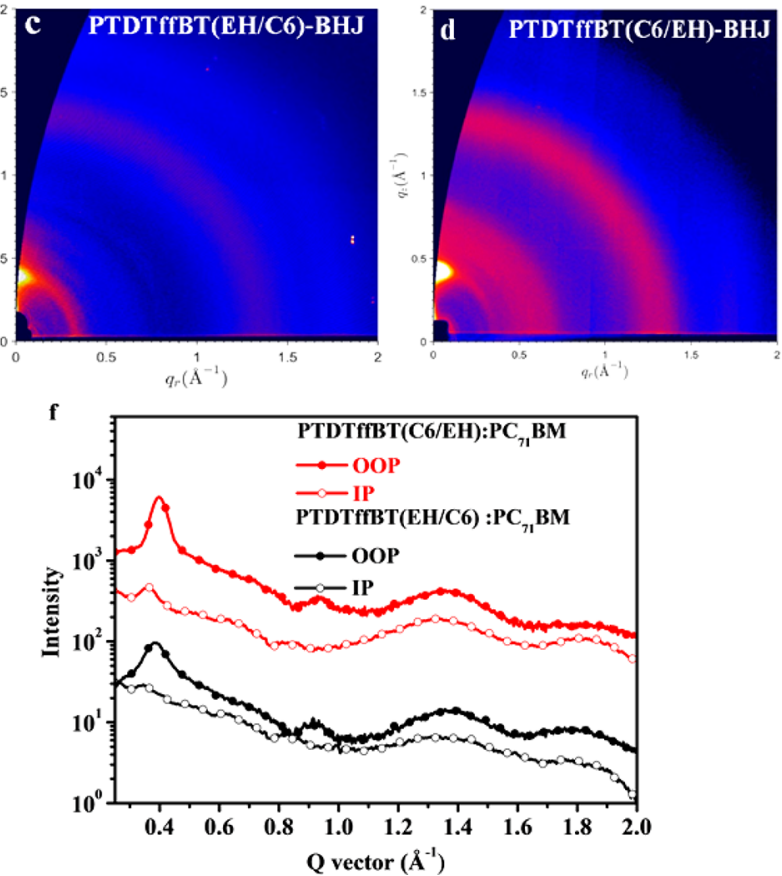

Figure 5. ( $a, b)$ GIWAXS patterns of the pristine polymer films and $(c, d)$ the polymer: $\mathrm{PC}_{71} \mathrm{BM}$ blend films. Out-of-plane (OOP) and in-plane (IP) profiles of (e) the neat films and (f) the optimized BHJ blend films.

from the SCLC method and partially accounts for the higher $J_{\text {sc }}, \mathrm{FF}$, and EQE response of the PTDTffBT(C6/ $\mathrm{EH}): \mathrm{PC}_{71} \mathrm{BM}$ device.

3.5. Film Morphology Characterization. Given the negligible effect of alkyl side chain interchanging between the donor and acceptor units along the conjugated backbone on the electronic structure of the resulting copolymers, the improved performance on exciton generation and dissociation, charge transport and recombination of the PTDTffBT(C6/ $\mathrm{EH}): \mathrm{PC}_{71} \mathrm{BM}$ device could most likely be ascribed to the more optimized molecular packing and phase separation in the $\mathrm{BHJ}$ blend. Tapping-mode atomic force microscopy (AFM) was employed to investigate the surface morphology of the $\mathrm{BHJ}$ blend films as presented in Figure S32. The BHJ blend with PTDTffBT(EH/C6) shows a featureless and smooth surface with a root-mean-square (RMS) roughness of $2.38 \mathrm{~nm}$. In contrast, the BHJ film of PTDTffBT(C6/EH) develops fibril structures with a RMS roughness of $9.15 \mathrm{~nm}$, indicating improved ordering of the components which is beneficial for charge transport. Grazing-incidence wide-angle X-ray scattering (GIWAXS) measurement was carried out as well to further disclose the intermolecular stacking distance, crystallite orientation, and crystallinity of the two copolymers in both the pure and the BHJ blend films. Figure 5a-d are GIWAXS patterns of the pristine polymer films and the corresponding $\mathrm{BHJ}$ blend films. As shown in Figure 5e, the diffraction scans for the neat PTDTffBT $(\mathrm{C} 6 / \mathrm{EH})$ show a strong out-of-plane (OOP) (100) reflection at $q_{z}$ of $0.42 \AA^{-1}$ corresponding to a lamellar $d$-spacing of $14.95 \AA$ and an in-plane (IP) (010) reflection at $q_{\mathrm{r}}$ of $1.78 \AA^{-1}$ corresponding to a $\pi-\pi$ stacking $d$ spacing of $3.53 \AA$, indicating a typical edge-on orientation of the polymer crystals. A much weaker in-plane (IP) (100) reflection at $q_{\mathrm{r}}$ of $0.36 \AA^{-1}(d=17.44 \AA)$ can also be observed without an obviously detectable OOP (010) feature, suggesting the existence of a part of face-on orientation. For the neat PTDTffBT(EH/C6) film, the OOP (100) reflection at $q_{\mathrm{z}}$ of $0.40 \AA^{-1}$ corresponds to a $d$-spacing of $15.70 \AA$ and the IP (010) reflection at $q_{\mathrm{r}}$ of $1.72 \AA^{-1}$ corresponds to the $d$ spacing value of $3.65 \AA$. Additionally, a blunt IP (100) reflection at $\sim 0.34 \AA^{-1}(d=18.47 \AA)$ can also be observed with a negligible OOP (010) feature. Briefly, the neat films of both copolymers present bimodal molecular packing with preferential edge-on orientations. The stacking space distances between the alkyl chains and between the conjugated backbones $(\pi-\pi$ stacking) are improved in the PTDTffBT(C6/EH) film with enhanced crystallinity. Such stronger aggregation tendency of PTDTffBT $(\mathrm{C} 6 / \mathrm{EH})$ in the film can be attributed to side chain tuning on the molecular conformation and larger dipole moment as demonstrated above. When blended with $\mathrm{PC}_{71} \mathrm{BM}$ to form a $\mathrm{BHJ}$ film, the bimodal molecular packing of the polymers with preferential edge-on orientation remains in the PTDTffBT(C6/ $\mathrm{EH}): \mathrm{PC}_{71} \mathrm{BM}$ blend as shown in Figure 5f. The typical reflection at $\sim 1.34 \AA^{-1}(d=4.67 \AA)$ along both the IP and OOP direction refers to $\mathrm{PC}_{71} \mathrm{BM}$ aggregation. The OOP (100) reflection at $0.40 \AA^{-1}(d=15.70 \AA)$ and the IP $(010)$ reflection at $1.82 \AA^{-1}(d=3.45 \AA)$ can be observed with increased lamellar and compressed $\pi-\pi$ stacking distance compared to that of the neat polymer film. It is interesting that the IP (100) reflection of PTDTffBT $(\mathrm{C} 6 / \mathrm{EH})$ remains almost at the same $q_{\mathrm{r}}(\sim 0.36 \AA, d=17.44 \AA)$ both in the neat and $\mathrm{BHJ}$ blend films. In the case of the PTDTffBT $(\mathrm{EH} /$ $\mathrm{C6}): \mathrm{PC}_{71} \mathrm{BM}$ blend, an obvious OOP (100) reflection of PTDTffBT(EH/C6) at $0.38 \AA^{-1}(d=16.53 \AA)$ can be observed besides the reflections of $\mathrm{PC}_{71} \mathrm{BM}$ aggregation, suggesting a dominating edge-on orientation of the polymer crystals in spite of no corresponding evident IP (010) diffraction observed. The most distinctive feature on molecular packing within the PTDTffBT $(\mathrm{C} 6 / \mathrm{EH}): \mathrm{PC}_{71} \mathrm{BM}$ blend compared with the $\mathrm{PTDTffBT}(\mathrm{EH} / \mathrm{C6}): \mathrm{PC}_{71} \mathrm{BM}$ blend is the obvious coexistence of a certain amount of face-on oriented packing besides the obvious edge-on orientation with 
respect to the substrate with improved $\pi-\pi$ interaction. Although face-on orientation can be observed faintly as well for PTDTffBT(EH/C6) in its BHJ blend, the crystallinity of the face-on crystals is much weaker from the IP (100) peak than that of PTDTffBT $(\mathrm{C} 6 / \mathrm{EH})$ in its BHJ blend. Such pronounced molecular packing most likely accounts for the noticeable enhancement of the charge transport with suppressed charge recombination, leading to improved $J_{\mathrm{sc}}$ and $\mathrm{FF}$ in comparison with the PTDTffBT $(\mathrm{EH} / \mathrm{C} 6): \mathrm{PC}_{71} \mathrm{BM}$ device.

\section{CONCLUSION}

In conclusion, two isomeric $\mathrm{D}-\mathrm{A}$ alternating copolymers consisting the donor unit of $3^{\prime}, 4^{\prime}$-dialkyl-2,2' $: 5^{\prime}, 2^{\prime \prime}$-terthiophene and the acceptor unit of 5,6-difluoro-4,7-di(4-alkylthiophen-2-yl)benzo[c] $[1,2,5]$ thiadiazole were synthesized and characterized by exchanging alkyl side chain of hexyl and branched 2-ethylhexyl between the donor and acceptor units. Positioning the alkyl chains of 2-ethylhexyl on the acceptor units and hexyl on the donor units resulted in slightly decreased dihedral angles within the donor unit and slightly increased dihedral angles between the donor and the acceptor units. Such subtle structure perturbation by the backbone steric distortions from the dihedral angles is found to show negligible impact on polymer electronic structures but lead to distinctive film microstructure. GIWAXS results reveals that the copolymer with such positioned alkyl side chains (PTDTffBT(C6/EH)) shows higher quality of molecular packing with enhanced $\pi-\pi$ stacking, crystallite orientation, and crystallinity while ensuring comparable solubility to its counterpart polymer (PTDTffBT(EH/C6)), which were accordingly translated into much improved polymer solar cell device performance. This complementary insight on the impact of backbone steric distortions on the molecular conformation, film morphology, and the PSC device performance could provide meaningful guidance for the chemical structure optimization of polymer donors toward highly efficient PSCs.

\section{ASSOCIATED CONTENT}

\section{S Supporting Information}

The Supporting Information is available free of charge on the ACS Publications website at DOI: 10.1021/acsaem.8b00948.

General information on materials, TGA, ground-state dipole moment of TDTffBT(EH/C6) and TDTffBT$(\mathrm{C} 6 / \mathrm{EH})$, temperature-dependent $\mathrm{UV}$-vis absorption spectra of the two copolymers in diluted dichlorobenzene solution, cyclic voltammogram curves of the copolymers, detailed photovoltaic performance optimization, $J-V$ curves of electron- and hole-only devices under dark, and tapping mode AFM images (PDF)

\section{AUTHOR INFORMATION}

\section{Corresponding Authors}

*E-mail: shengqiang@whut.edu.cn (S.X.).

*E-mail: xhlu@phy.cuhk.edu.hk (X.L.).

*E-mail: wyou@unc.edu (W.Y.).

\section{ORCID}

Shengqiang Xiao: 0000-0001-7644-8491

Wei You: 0000-0003-0354-1948

\section{Notes}

The authors declare no competing financial interest.

\section{ACKNOWLEDGMENTS}

S.X. thanks the National Natural Science Foundation of China (21673170) and State Key Laboratory of Advanced Technology for Materials Synthesis and Processing (2017-KF-9) for support. X.L. acknowledges the financial support from RGC of Hong Kong GRF (14314216) and beam time and technical supports provided by 23A SWAXS beamline at NSRRC, Hsinchu.

\section{REFERENCES}

(1) Kang, H.; Kim, G.; Kim, J.; Kwon, S.; Kim, H.; Lee, K. BulkHeterojunction Organic Solar Cells: Five Core Technologies for Their Commercialization. Adv. Mater. 2016, 28, 7821-7861.

(2) Lu, L.; Zheng, T.; Wu, Q.; Schneider, A. M.; Zhao, D.; Yu, L. Recent Advances in Bulk Heterojunction Polymer Solar Cells. Chem. Rev. 2015, 115, 12666-12731.

(3) Kang, H.; Lee, W.; Oh, J.; Kim, T.; Lee, C.; Kim, B. J. From Fullerene-Polymer to All-Polymer Solar Cells: The Importance of Molecular Packing, Orientation, and Morphology Control. Acc. Chem. Res. 2016, 49, 2424-2434.

(4) Xiao, S.; Zhang, Q.; You, W. Molecular Engineering of Conjugated Polymers for Solar Cells: An Updated Report. Adv. Mater. 2017, 29, 1601391.

(5) Rivnay, J.; Mannsfeld, S. C. B.; Miller, C. E.; Salleo, A.; Toney, M. F. Quantitative Determination of Organic Semiconductor Microstructure from the Molecular to Device Scale. Chem. Rev. 2012, 112, 5488-5519.

(6) Ye, L.; Zhang, S.; Huo, L.; Zhang, M.; Hou, J. Molecular Design toward Highly Efficient Photovoltaic Polymers Based on TwoDimensional Conjugated Benzodithiophene. Acc. Chem. Res. 2014, 47, $1595-1603$.

(7) Zhang, Q.; Kelly, M. A.; Bauer, N.; You, W. The Curious Case of Fluorination of Conjugated Polymers for Solar Cells. Acc. Chem. Res. 2017, 50, 2401-2409.

(8) Cai, Y.; Huo, L.; Sun, Y. Recent Advances in Wide-Bandgap Photovoltaic Polymers. Adv. Mater. 2017, 29, 1605437.

(9) Yin, Z.; Wei, J.; Zheng, Q. Interfacial Materials for Organic Solar Cells: Recent Advances and Perspectives. Adv. Sci. 2016, 3, 1500362.

(10) Yao, H.; Ye, L.; Zhang, H.; Li, S.; Zhang, S.; Hou, J. Molecular Design of Benzodithiophene-Based Organic Photovoltaic Materials. Chem. Rev. 2016, 116, 7397-7457.

(11) Liu, C.; Wang, K.; Gong, X.; Heeger, A. J. Low Bandgap Semiconducting Polymers for Polymeric Photovoltaics. Chem. Soc. Rev. 2016, 45, 4825-4846.

(12) Wu, J.-S.; Cheng, S.-W.; Cheng, Y.-J.; Hsu, C.-S. DonorAcceptor Conjugated Polymers Based on Multifused Ladder-Type Arenes for Organic Solar Cells. Chem. Soc. Rev. 2015, 44, 1113-1154.

(13) Zhang, K.; Hu, Z.; Sun, C.; Wu, Z.; Huang, F.; Cao, Y. Toward Solution-Processed High-Performance Polymer Solar Cells: from Material Design to Device Engineering. Chem. Mater. 2017, 29, 141148.

(14) Chen, W.; Yang, X.; Long, G.; Wan, X.; Chen, Y.; Zhang, Q. A Perylene Diimide (PDI)-Based Small Molecule with Tetrahedral Configuration as a Non-Fullerene Acceptor for Organic Solar Cells. J. Mater. Chem. C 2015, 3, 4698-4705.

(15) Chen, W.; Zhang, Q. Recent Progress in Non-Fullerene Small Molecule Acceptors in Organic Solar Cells (OSCs). J. Mater. Chem. C 2017, 5, 1275-1302.

(16) Sun, H.; Song, X.; Xie, J.; Sun, P.; Gu, P.; Liu, C.; Chen, F.; Zhang, Q.; Chen, Z.-K.; Huang, W. PDI Derivative through FineTuning the Molecular Structure for Fullerene-Free Organic Solar Cells. ACS Appl. Mater. Interfaces 2017, 9, 29924-29931.

(17) Zhao, J.; Li, Y.; Yang, G.; Jiang, K.; Lin, H.; Ade, H.; Ma, W.; Yan, H. Efficient Organic Solar Cells Processed from Hydrocarbon Solvents. Nat. Energy 2016, 1, 15027.

(18) Fan, B.; Ying, L.; Wang, Z.; He, B.; Jiang, X.-F.; Huang, F.; Cao, Y. Optimisation of Processing Solvent and Molecular Weight for the Production of Green-Solvent-Processed All-Polymer Solar Cells with 
a Power Conversion Efficiency over 9\%. Energy Environ. Sci. 2017, 10, $1243-1251$

(19) Li, Z.; Xu, X.; Zhang, W.; Meng, X.; Genene, Z.; Ma, W.; Mammo, W.; Yartsev, A.; Andersson, M. R.; Janssen, R. A. J.; Wang, E. 9.0\% Power Conversion Efficiency from Ternary All-Polymer Solar Cells. Energy Environ. Sci. 2017, 10, 2212-2221.

(20) Li, S.; Ye, L.; Zhao, W.; Yan, H.; Yang, B.; Liu, D.; Li, W.; Ade, H.; Hou, J. A Wide Band Gap Polymer with a Deep Highest Occupied Molecular Orbital Level Enables 14.2\% Efficiency in Polymer Solar Cells. J. Am. Chem. Soc. 2018, 140, 7159-7167.

(21) Zhao, W.; Li, S.; Yao, H.; Zhang, S.; Zhang, Y.; Yang, B.; Hou, J. Molecular Optimization Enables over 13\% Efficiency in Organic Solar Cells. J. Am. Chem. Soc. 2017, 139, 7148-7151.

(22) Sun, J.; Ma, X.; Zhang, Z.; Yu, J.; Zhou, J.; Yin, X.; Yang, L.; Geng, R.; Zhu, R.; Zhang, F.; Tang, W. Dithieno[3,2-b:2',3'-d]pyrrol Fused Nonfullerene Acceptors Enabling Over 13\% Efficiency for Organic Solar Cells. Adv. Mater. 2018, 30, 1707150.

(23) Zhou, H.; Yang, L.; You, W. Rational Design of High Performance Conjugated Polymers for Organic Solar Cells. Macromolecules 2012, 45, 607-632.

(24) Li, Y. Molecular Design of Photovoltaic Materials for Polymer Solar Cells: Toward Suitable Electronic Energy Levels and Broad Absorption. Acc. Chem. Res. 2012, 45, 723-733.

(25) Yang, M.; Lau, T.-K.; Xiao, S.; Gao, J.; Wang, W.; Lu, X.; Zhang, S.; Wu, J.; Zhan, C.; You, W. A Ladder-type Heteroheptacene 12H-Dithieno[2',3':4,5] thieno[3,2-b:2',3'-h] fluorene Based D-A Copolymer with Strong Intermolecular Interactions toward Efficient Polymer Solar Cells. ACS Appl. Mater. Interfaces 2017, 9, 3515935168.

(26) Liu, Y.; Zhao, J.; Li, Z.; Mu, C.; Ma, W.; Hu, H.; Jiang, K.; Lin, H.; Ade, H.; Yan, H. Aggregation and Morphology Control Enables Multiple Cases of High-Efficiency Polymer Solar Cells. Nat. Commun. 2014, 5, 5293.

(27) Hu, Z.; Ying, L.; Huang, F.; Cao, Y. Towards a Bright Future: Polymer Solar Cells with Power Conversion Efficiencies over 10\%. Sci. China: Chem. 2017, 60, 571-582.

(28) Lei, T.; Wang, J.-Y.; Pei, J. Roles of Flexible Chains in Organic Semiconducting Materials. Chem. Mater. 2014, 26, 594-603.

(29) Stalder, R.; Mei, J.; Graham, K. R.; Estrada, L. A.; Reynolds, J. R. Isoindigo, a Versatile Electron-Deficient Unit For High-Performance Organic Electronics. Chem. Mater. 2014, 26, 664-678.

(30) Graham, K. R.; Cabanetos, C.; Jahnke, J. P.; Idso, M. N.; El Labban, A.; Ngongang Ndjawa, G. O.; Heumueller, T.; Vandewal, K.; Salleo, A.; Chmelka, B. F.; Amassian, A.; Beaujuge, P. M.; McGehee, M. D. Importance of the Donor:Fullerene Intermolecular Arrangement for High-Efficiency Organic Photovoltaics. J. Am. Chem. Soc. 2014, 136, 9608-9618.

(31) Oh, J.; Kranthiraja, K.; Lee, C.; Gunasekar, K.; Kim, S.; Ma, B.; Kim, B. J.; Jin, S. H. Side-Chain Fluorination: An Effective Approach to Achieving High-Performance All-Polymer Solar Cells with Efficiency Exceeding 7\%. Adv. Mater. 2016, 28, 10016-10023.

(32) Han, L.; Jiang, H.; Ouyang, D.; Chen, W.; Hu, T.; Wang, J.; Wen, S.; Sun, M.; Yang, R. Cyclic Alkyl Chains Promote the Polymer Self-Assembly and Packing Orders for Solar Cells. Nano Energy 2017, $36,110-117$.

(33) Zhang, Z.-G.; Li, Y. Side-Chain Engineering of High-Efficiency Conjugated Polymer Photovoltaic Materials. Sci. China: Chem. 2015, 58, 192-209.

(34) Lee, C.; Kang, H.; Lee, W.; Kim, T.; Kim, K. H.; Woo, H. Y.; Wang, C.; Kim, B. J. High-Performance All-Polymer Solar Cells Via Side-Chain Engineering of the Polymer Acceptor: The Importance of the Polymer Packing Structure and the Nanoscale Blend Morphology. Adv. Mater. 2015, 27, 2466-2471.

(35) Osaka, I.; Saito, M.; Koganezawa, T.; Takimiya, K. ThiopheneThiazolothiazole Copolymers: Significant Impact of Side Chain Composition on Backbone Orientation and Solar Cell Performances. Adv. Mater. 2014, 26, 331-338.

(36) Chen, X.; Zhang, Z.; Ding, Z.; Liu, J.; Wang, L. Diketopyrrolopyrrole-Based Conjugated Polymers Bearing Branched
Oligo(Ethylene Glycol) Side Chains for Photovoltaic Devices. Angew. Chem., Int. Ed. 2016, 55, 10376-10380.

(37) Su, Y.-W.; Lin, Y.-C.; Wei, K.-H. Evolving Molecular Architectures of Donor-Acceptor Conjugated Polymers for Photovoltaic Applications: from One-Dimensional to Branched to TwoDimensional Structures. J. Mater. Chem. A 2017, 5, 24051-24075.

(38) Yang, Y.; Zhang, Z.-G.; Bin, H.; Chen, S.; Gao, L.; Xue, L.; Yang, C.; Li, Y. Side-Chain Isomerization on an n-Type Organic Semiconductor ITIC Acceptor Makes 11.77\% High Efficiency Polymer Solar Cells. J. Am. Chem. Soc. 2016, 138, 15011-15018.

(39) Hoang, Q. V.; Song, C. E.; Moon, S.-J.; Lee, S. K.; Lee, J.-C.; Kim, B. J.; Shin, W. S. Asymmetric Electron-Donating 4-Alkyl-8alkoxybenzo[1,2-b:4,5-b']dithiophene Unit for Use in High-Efficiency Bulk Heterojunction Polymer Solar Cells. Macromolecules 2015, 48, 3918-3927.

(40) Jiang, J.-M.; Lin, H.-K.; Lin, Y.-C.; Chen, H.-C.; Lan, S.-C.; Chang, C.-K.; Wei, K.-H. Side Chain Structure Affects the Photovoltaic Performance of Two-Dimensional Conjugated Polymers. Macromolecules 2014, 47, 70-78.

(41) Su, Y.-W.; Lan, S.-C.; Wei, K.-H. Organic photovoltaics. Mater. Today 2012, 15, 554-562.

(42) Hu, H.; Chow, P. C. Y.; Zhang, G.; Ma, T.; Liu, J.; Yang, G.; Yan, H. Design of Donor Polymers with Strong TemperatureDependent Aggregation Property for Efficient Organic Photovoltaics. Acc. Chem. Res. 2017, 50, 2519-2528.

(43) Yao, H.; Li, Y.; Hu, H.; Chow, P. C. Y.; Chen, S.; Zhao, J.; Li, Z.; Carpenter, J. H.; Lai, J. Y. L.; Yang, G.; Liu, Y.; Lin, H.; Ade, H.; Yan, H. A Facile Method to Fine-Tune Polymer Aggregation Properties and Blend Morphology of Polymer Solar Cells Using Donor Polymers with Randomly Distributed Alkyl Chains. Adv. Energy Mater. 2018, 8, 1701895.

(44) Hu, H.; Jiang, K.; Yang, G.; Liu, J.; Li, Z.; Lin, H.; Liu, Y.; Zhao, J.; Zhang, J.; Huang, F.; Qu, Y.; Ma, W.; Yan, H. Terthiophene-Based D-A Polymer with an Asymmetric Arrangement of Alkyl Chains That Enables Efficient Polymer Solar Cells. J. Am. Chem. Soc. 2015, 137, 14149-14157.

(45) Che, X.; Chung, C. L.; Hsu, C. C.; Liu, F.; Wong, K. T.; Forrest, S. R. Donor-Acceptor-Acceptor's Molecules for VacuumDeposited Organic Photovoltaics with Efficiency Exceeding 9\%. Adv. Energy Mater. 2018, 8, 1703603.

(46) Cho, H. H.; Kim, S.; Kim, T.; Sree, V. G.; Jin, S. H.; Kim, F. S.; Kim, B. J. Design of Cyanovinylene-Containing Polymer Acceptors with Large Dipole Moment Change for Efficient Charge Generation in High-Performance All-Polymer Solar Cells. Adv. Energy Mater. 2018, 8, 1701436.

(47) Jo, J. W.; Jung, J. W.; Wang, H.-W.; Kim, P.; Russell, T. P.; Jo, W. H. Fluorination of Polythiophene Derivatives for High Performance Organic Photovoltaics. Chem. Mater. 2014, 26, 4214-4220.

(48) Kyaw, A. K. K.; Wang, D. H.; Gupta, V.; Leong, W. L.; Ke, L.; Bazan, G. C.; Heeger, A. J. Intensity Dependence of Current-Voltage Characteristics and Recombination in High-Efficiency SolutionProcessed Small-Molecule Solar Cells. ACS Nano 2013, 7, 45694577.

(49) Gao, J.; Wang, W.; Zhang, S.; Xiao, S.; Zhan, C.; Yang, M.; Lu, X.; You, W. Distinction between PTB7-Th Samples Prepared from $\mathrm{Pd}\left(\mathrm{PPh}_{3}\right)_{4}$ and $\mathrm{Pd}_{2}(\mathrm{dba})_{3} / \mathrm{P}(\mathrm{o}-\mathrm{tol})_{3}$ Catalysed Stille Coupling Polymerization and the Resultant Photovoltaic Performance. J. Mater. Chem. A 2018, 6, 179-188.

(50) Kyaw, A. K. K.; Wang, D. H.; Wynands, D.; Zhang, J.; Nguyen, T.-Q.; Bazan, G. C.; Heeger, A. J. Improved Light Harvesting and Improved Efficiency by Insertion of an Optical Spacer $(\mathrm{ZnO})$ in Solution-Processed Small-Molecule Solar Cells. Nano Lett. 2013, 13, 3796-3801. 